\title{
Determinants of Vaccination Coverage Against Human Papillomavirus in 10-year-old Girls in 2016 in Rural Senegal
}

\author{
Adama Faye $^{1}$, Sidy Ndiaye ${ }^{2}$, Khadim Niang ${ }^{1}$, Mamadou Ndiaye $^{2}$, Anta Tal-Dia ${ }^{1}$ \\ ${ }^{1}$ Department of Preventive Medicine and Public Health, Cheikh Anta Diop University, Dakar, Senegal \\ ${ }^{2}$ Ministry of Health and Social Action, Dakar, Senegal
}

Email address:

adamfaye94@gmail.com (A. Faye), adama.faye@ucad.edu.sn (A. Faye)

To cite this article:

Adama Faye, Sidy Ndiaye, Khadim Niang, Mamadou Ndiaye, Anta Tal-Dia. Determinants of Vaccination Coverage Against Human Papillomavirus in 10-year-old Girls in 2016 in Rural Senegal. Science Journal of Public Health. Vol. 5, No. 6, 2017, pp. 464-468. doi: 10.11648/j.sjph.20170506.19

Received: September 16, 2017; Accepted: October 11, 2017; Published: November 24, 2017

\begin{abstract}
Cervical cancer is the first gynecological cancer in Senegal. As part of the cancer control plan, the Ministry of Health and Social Action conducted a pilot phase of HPV vaccination in the districts of Dakar and Mekhe between 2014 and 2016. The objective of this survey is to study the determinants of HPV vaccination coverage in 10-year-old girls in 2016 in the Mekhe health district. This is a descriptive cross-sectional epidemiological study for analytical purposes. A two-stage survey was conducted. The data were collected during an individual interview at the homes of the mothers. The compendium focused on personal characteristics, knowledge and practices on immunization. Full vaccination coverage was determined. Logistic regression was used to identify factors associated with immunization coverage. Respondents were 300 The mean age was $35 \pm$ 9.64 years. Mothers who knew how to prevent cervical cancer were 171 or $57 \%$ [95\% CI: 51.2-62.7]. Immunization coverage for girls aged 10 years was $86.3 \%$ [95\% CI: 81.9-90.0]. The discontinuation between the first and second dose of the vaccine was $6.5 \%$ [95\% CI: 3.9-10.1]. HPV vaccine coverage was related to the residence environment (OR $=3,18$ [95\% CI: $1.34-$ 7.56]); $(\mathrm{OR}=22.02,[95 \% \mathrm{CI}: 4.2-113.4])$ and information for mothers $(\mathrm{OR}=10.92$ [95\% CI: 2.93-40.64]). Vaccination against HPV is a preventive activity that requires the collaboration with the education sector and a good proximity communication.
\end{abstract}

Keywords: Immunization Coverage, HPV, Girl, Determinants, Senegal

\section{Introduction}

Cervical cancer is a major public health problem. In the world, it ranges second of cancers affecting the woman [1]. This cancer is more common in sub-Saharan Africa with 75,000 new cases and nearly 50,000 deaths each year [2]. In Senegal, it comes to the first place among all cancers diagnosed at the Curie institute of Dakar [3]. Vaccination with Human Papilloma Virus (HPV) is an effective strategy for the prevention of cervical cancer [4]. However, it is not yet integrated into the vaccination program in Senegal. The assessment of acceptability in the countries where it was introduced shows varied rates depending on the country and the used strategy. For a school based approach, vaccine coverage was $82.6 \%$ in Peru, $82.9 \%$ in Uganda and $96.1 \%$ in Vietnam. As for a campaign based strategy in India, immunization coverage was $77.2 \%$ [4], and for the monthly appointment strategy, vaccination coverage was $68.4 \%$.

The study of the factors associated with acceptability showed that the main reason for non-vaccination was school absenteeism [4]. The authors recommend reinforcing motivations to improve acceptability. In Nigeria, the high vaccine coverage was linked mainly to the level of knowledge of mothers [6]. In Kenya, however, the barriers identified were lack of information on vaccine, school absenteeism, potential side effects and low school enrollment [7]. In Mali, the main barrier identified in this study was the poor decision-making power of the target [8].

The identification of barriers linked to immunization will make available to the health authorities evidence to make decisions with a scientific basis. These data will help develop more appropriate and better targeted strategies in order to improve vaccine coverage against HPV. The objective of this 
study is to identify the factors associated with the acceptability of HPV vaccination in Senegal.

\section{Method}

\subsection{Study Design}

It is a cross-sectional, descriptive and analytical study.

\subsection{Study Population}

The study concerned girls who were born between 1 December 2005 and 30 November 2006 residing in the Mekhe health district and were 10 at the time of the survey. The campaign based vaccination in two doses for the quadrivalent HPV vaccine took place in schools, in coranic schools; and in an advanced strategy, it took place in the health posts and in the public squares in the villages where health posts and schools are not available.

\subsection{Sampling}

The sample size is calculated using the Schwartz formula.

$$
\mathrm{N}=\left[\mathrm{Z} \alpha^{2} . \mathrm{P}(1-\mathrm{P})\right] / \mathrm{e}^{2} .
$$

$\mathrm{Z} \alpha:=1.96$ : discrepancy corresponding to the risk granted $(\alpha=5 \%, z \alpha=1.96)$.

$\mathrm{P}:$ administrative coverage $\mathrm{p}=0.92 \mathrm{q}=(1-\mathrm{p})=0.08$.

E: margin of error (set at 5\%).

The sample size thus calculated is 226 girls. Taking into account a non-response rate of $10 \%$, we end up with a final size of 300 girls. The two-stage cluster sampling method was used. The first stage of sampling consisted of villages and neighborhoods, the second stage consisting of the households of the geographical areas of the study. First, we list the villages and neighborhoods with their cumulated populations. Systematic random sampling was carried out with a sampling interval marked $\mathrm{S}$ calculated according to the formula:

$$
S=\frac{\text { Total Population of villages and districts }(N)}{\text { nomber of cluster of the sampling }}=\frac{171646}{30}=5722
$$

A selection of the location of the clusters in the administrative units was made using a random number for the first cluster. This random number is between $\mathrm{N}$ and $\mathrm{S}$. In each cluster, the first house was chosen at random according to the bottle method. The second house to visit was the one to the right of the first one and the evolution took place gradually from the first house until we end up with the number of children to be recruited for the cluster.

\subsection{Data Collect}

The data collection was done on the basis of an anonymous questionnaire, closed-ended, administered by an interviewer at the respondent's home. The questionnaire was administered with the verbal consent of the respondent. During the training, the translation and the way of asking the questions in local languages were clarified. The questionnaire is first tested on about 20 mothers of children after the training of the investigators. This allowed us to observe the respondents' response to the survey. The data collected included the socio-demographic characteristics of the mother and child, the mother's knowledge, the child's immunization status. The vaccination status of the child was assessed via the card and the vaccination history. A girl is considered fully vaccinated if she received two doses of the quadrivalent HPV vaccine during the HPV vaccination demonstration project.

\subsection{Data Analysis}

The data was analyzed using software $\mathrm{R}$ version 3.1.1. Quantitative variables were expressed by the average associated with the standard deviation and the qualitative variables as a percentage. The comparison between the dependent variable vaccination coverage and the qualitative variables was carried out using a Pearson chi-square test.

A downward logistic regression was performed. The vaccine status is the dependent variable to be modeled. All independent variables with a p less than 0.25 [9] in the bivariate analysis were included in the multivariate analysis. The comparison of the models was done by the test of the likelihood ratio with a top-down procedure. The suitability of the model was studied by the Hosmer and Lemeshow test. The association measure was the adjusted odds ratio (OR) and its $95 \%$ confidence interval.

\section{Results}

A total of 330 women were interviewed. The mean age was 35 years ( \pm 9.64 years). Adolescents accounted for $8.3 \%$. Among the interviewed women, $94.0 \%$ were married, $90.0 \%$ resided in rural areas and $37.0 \%$ were educated. Women with income-generating activities accounted for $44.0 \%$. Schooled girls were $65.1 \%$ (table 1$)$.

\begin{tabular}{|c|c|c|}
\hline Characteristics & $\begin{array}{l}\text { Absolute } \\
\text { frequencies }\end{array}$ & $\begin{array}{l}\text { Relative } \\
\text { frequencies (\%) }\end{array}$ \\
\hline \multicolumn{3}{|l|}{ Residence } \\
\hline Urban & 30 & 10,0 \\
\hline Rural & 270 & 90,0 \\
\hline \multicolumn{3}{|l|}{ Age (years) } \\
\hline$>24$ & 275 & 91,7 \\
\hline$<=44$ & 25 & 8,3 \\
\hline \multicolumn{3}{|l|}{ interviewed Profil } \\
\hline Mother & 234 & 78,0 \\
\hline Guardian & 66 & 22,0 \\
\hline \multicolumn{3}{|l|}{ Marital status } \\
\hline married & 282 & 94,0 \\
\hline Not married & 18 & 6,0 \\
\hline \multicolumn{3}{|l|}{ Education } \\
\hline Yes & 111 & 37,0 \\
\hline No & 189 & 63,0 \\
\hline \multicolumn{3}{|c|}{ Income Generating Activity } \\
\hline Yes & 132 & 44,0 \\
\hline No & 168 & 56,0 \\
\hline
\end{tabular}

Table 1. Sociodemographic Characteristics of Interviewed. 


\begin{tabular}{lll}
\hline Characteristics & $\begin{array}{l}\text { Absolute } \\
\text { frequencies }\end{array}$ & $\begin{array}{l}\text { Relative } \\
\text { frequencies (\%) }\end{array}$ \\
\hline$>5$ & 30 & 6,6 \\
$<=5$ & 270 & 93,4 \\
School enrollment & & \\
French School & 190 & 63,3 \\
Koranic School & 90 & 30,0 \\
French and Arabic School & 12 & 4,0 \\
No & 8 & 2,7 \\
Knowledge of cervical cancer & & \\
Yes & 173 & 57,7 \\
No & 127 & 42,3 \\
Knowledge of HPV infection & & \\
Yes & 19 & 6,3 \\
No & 281 & 93,7 \\
Knowledge Link between HPV & & \\
and Cervical Cancer & & 7 \\
Yes & 21 & 93 \\
No & 279 & \\
Knowledge of prevention means & & 57 \\
Yes & 171 & 43 \\
No & 129 & \\
\hline
\end{tabular}

\begin{tabular}{llll}
\hline & \multicolumn{3}{l}{ Welcoming in facilities } \\
& satisfactory & 288 & 96 \\
& not satisfactory & 12 & 4 \\
Waiting time in facilities & satisfactory & 276 & 92 \\
& not satisfactory & 24 & 8 \\
Post-Injection Event & Yes & 32 & 11,6 \\
& No & 268 & 89,4 \\
Possession of card & & & \\
& Yes & 144 & 48,0 \\
Vaccination & No & 156 & 52,0 \\
& & & \\
Place of vaccination & Yes & 259 & 86,3 \\
& No & 41 & 13,7 \\
& At school & 178 & 59,3 \\
& Elsewhere & 41 & 13,7 \\
\hline
\end{tabular}

Mothers and guardians who had knowledge about cervical cancer were $57.7 \%$, while only $6.3 \%$ knew about HPV. The respondents who knew the link between HPV infection and cervical cancer were $7 \%$. Nearly $90 \%$ were aware of the HPV vaccination campaign. Radio (62\%) was mentioned as the most common source of information, followed by community relays $(59.0 \%)$. Teachers and caregivers were
$10.7 \%$ and $9.3 \%$ respectively. The message "cervical cancer is serious" was understood by $86.7 \%$ of women during the vaccination against HPV. Vaccination as the main means of prevention was understood by $17.3 \%$.

Girls who received at least one dose of HPV vaccine were 92.3\%. The possession rate of an HPV vaccination card was $57.8 \%$. Discontinuation between the first and second dose of the vaccine was $6.5 \%$. Immunization coverage was $86.3 \%$ including $50.0 \%$ per card and $36.3 \%$ per history. The reasons for abandoning immunization were the absence of the girl (44.4\%), the absence of information $(22.2 \%)$ and the parents or the daughter being on travel $(30.5 \%)$. Eleven percent of the vaccinated girls experienced post-vaccination adverse effects. These were mainly pain $(50.0 \%)$, fever $(36.4 \%)$ and dizziness $(36.4 \%)$. Self-medication was in $65.6 \%$ of the cases.

The proportion of fully vaccinated girls living in rural areas was $88.1 \%$ compared with $70.0 \%$ in urban areas $(p=0.011)$. Immunization coverage for girls with adult mothers was $85.8 \%$ versus $92.0 \%$ for the others $(p=0.30)$. The proportion of girls who were fully immunized was not associated with the mother's education level $(p=0.68)$ (table 2$)$. HPV vaccination coverage is not related to the practice of an income-generating activity of the mother or caregiver. Immunization coverage for schooled girls was $88 \%$ compared to $25 \%$ for girls nonschooled girls $(p=0.0001)$. The level of knowledge of mothers and guardians did not influence the vaccination of girls against $\operatorname{HPV}(\mathrm{p}=0.82)$.

Immunization coverage among girls whose mothers / guardians have knowledge of the link between HPV infection and cervical cancer was $90.5 \%$ compared to 86.0 among mothers / caregivers $(p=0.43)$. HPV vaccination coverage for girls whose mothers / guardians were aware of the HPV vaccination campaign was $87.9 \%$. This proportion was $40 \%$ for those whose mothers / caregivers were not informed (table 2).

Girls living in rural areas were three times more likely to be fully immunized than girls in urban areas. Girls whose mothers were informed about the vaccination campaign were 10 times more likely to be fully vaccinated than those whose mothers and guardians were not informed $(\mathrm{OR}=10.92$ [CI: 2 , 93-40, 64]) (table 3).

Table 2. Distribution of Vaccination According to the Characteristics of the Respondents.

\begin{tabular}{|c|c|c|c|}
\hline & & Immunization n (\%) & $\mathbf{p}$ \\
\hline \multirow{2}{*}{ Residence } & Rural & $238(88,1)$ & 0,0113 \\
\hline & Urban & $21(70,0)$ & \\
\hline \multirow{2}{*}{ Age (years) } & $>24$ ans & $236(85,8)$ & 0,30 \\
\hline & $<=44$ ans & $23(92,0)$ & \\
\hline \multirow{2}{*}{ Instruction } & Yes & $97(87,4)$ & 0,68 \\
\hline & No & $162(85,7)$ & \\
\hline \multirow{2}{*}{ Income Generating Activity } & Yes & $114(86,4)$ & 0,98 \\
\hline & No & $145(86,3)$ & \\
\hline \multirow{2}{*}{ Rank of the child in the siblings } & Rang $<=5$ & $236(87,1)$ & 0,18 \\
\hline & Rang $>5$ & $23(79,3)$ & \\
\hline \multirow{2}{*}{ Scolarisation of child } & Yes & $202(88,0)$ & 0,001 \\
\hline & No & $98(25,0)$ & \\
\hline
\end{tabular}




\begin{tabular}{|c|c|c|c|}
\hline & & Immunization n (\%) & $\mathbf{p}$ \\
\hline \multirow{2}{*}{ Knowledge of cervical cancer } & Yes & $150(86,7)$ & 0,82 \\
\hline & No & $109(85,2)$ & \\
\hline \multirow{2}{*}{ Knowledge Link between HPV and Cervical Cancer } & Yes & $19(86,8)$ & 0,43 \\
\hline & No & $240(82,9)$ & \\
\hline \multirow{2}{*}{ Informations HPV vaccination } & Yes & $255(87,9)$ & 0,0006 \\
\hline & No & $40(40,0)$ & \\
\hline \multirow{2}{*}{ Welcoming in facilities } & Satisfactory & $251(87,2)$ & 0,06 \\
\hline & No satisfactory & $8(66,7)$ & \\
\hline \multirow{2}{*}{ Waiting time in facilities } & Satisfactory & $239(86,6)$ & 0,42 \\
\hline & No satisfactory & $20(83,3)$ & \\
\hline \multirow{2}{*}{ Place of vaccination } & School & $232(87,5)$ & 0,082 \\
\hline & Elsewhere & $27(77,1)$ & \\
\hline \multirow{2}{*}{ Sources informations (neighborhood godmother) } & Yes & $165(92,7)$ & 0,0001 \\
\hline & No & $94(77,0)$ & \\
\hline \multirow{2}{*}{ Information channel } & Proximity Communication & $209(91,3)$ & 0,0009 \\
\hline & Mass media & $50(70,4)$ & \\
\hline
\end{tabular}

Table 3. Factors Associated with Immunization (logistic Regression).

\begin{tabular}{|c|c|c|}
\hline & & OR IC 95\% \\
\hline \multirow{2}{*}{ Residence } & Rural & $3,18[1,34-7,56]$ \\
\hline & Urban & 1 \\
\hline \multirow{2}{*}{ Rank of The Child in The Siblings } & $<=5$ & $1,75(0,66-4,62)$ \\
\hline & $>5$ & 1 \\
\hline \multirow{2}{*}{ Scolarisation of Child } & Yes & $22,02[4,2 ; 113,4]$ \\
\hline & No & 1 \\
\hline Informations Hpv Vaccination & Oui & $10,92[2,93-40,64]$ \\
\hline \multirow{2}{*}{ Welcoming in Facilities } & Satisfaites & $1,60(0,32-7,85)$ \\
\hline & Non Satisfaites & 1 \\
\hline \multirow{2}{*}{ Place of Vaccination } & School & $2,08(0,87-4,96)$ \\
\hline & Elsewhere & 1 \\
\hline \multirow{2}{*}{ Sources Informations (Neighborhood Godmother) } & Yes & $3,78,[1,86-7,65]$ \\
\hline & No & 1 \\
\hline Information Channel & Proximity Communication & $4,38[2,218,71]$ \\
\hline
\end{tabular}

\section{Discussions}

The fully immunized girls were $86.3 \%$. This immunization coverage was associated with the girl's area of residence, schooling, information for mothers and the source of information. In this study, The complete vaccination was documented in $50 \%$ of the children. This raises the problem of keeping the vaccination card. This aspect must be taken into account when scaling up immunized girls, otherwise it will be difficult to evaluate or monitor the progress of this intervention. Vaccination coverage was $86.3 \%$. Similar results were found in Peru (88.9\%), Vietnam (83\%). A study in 21 developing countries that implemented vaccine demonstration projects against HPV showed vaccine coverage ranging from $67 \%$ in Georgia to $100 \%$ in Bolivia [10]. The differences noted are mainly due to the target and the strategies developed. This demonstrates the feasibility of vaccination against HPV in middle-income countries by adopting targeted immunization strategies in schools and health facilities and involving the community at all stages. In Rwanda [11], an active search for girls who missed their appointments was carried out systematically with the involvement of community members, the private sector and the media, achieving high coverage (93.3\%).
Girls living in rural areas were three times more likely to be fully immunized than girls in urban areas. Similar findings were noted in India [6] and Tanzania [12]. The difference in coverage according to the place of residence is explained by the socialization of the populations in rural areas, the inhabitants being essentially from the same families. Thus reference to an authority is often de rigueur and favors a greater adhesion of these populations of the rural world to the programs of health especially when they are free.

Immunization coverage was also associated with girls' schooling. In Tanzania [12] and Rwanda [11] similar results have been found. Ladner et al also found a positive association between immunization coverage and girls' education [10]. These concordant findings are explained at the contextual level because these studies have been carried out in countries that have implemented HPV vaccination demonstration projects in which the girls' immunization strategy at school has been mainly adopted with the involvement of the health, education and community sectors. In addition, the enrollment rate of $80 \%$ in Senegal has enabled schoolgirls to be more accessible to immunization services, while parents have been receptive to information coming from the school.

This study did not show a very significant association between vaccination coverage and knowledge about cervical 
cancer. However, girls whose mothers were informed about the vaccination campaign were more likely to be fully vaccinated. Proximity communication was significantly associated with high immunization coverage. Other studies have obtained similar results [10]. An analysis of the performance of HPV vaccination implementation programs in 21 countries has shown that the involvement of populations and communities through communication and target tracking is a positive factor associated with the completeness of HPV vaccination. However, the information must be better articulated, indeed, only $17.3 \%$ of mothers have retained "vaccination as the main means of prevention against cervical cancer".

\section{Conclusion}

The HPV vaccination project in the Mekhé district achieved vaccine coverage above the $70 \%$ target. HPV vaccination coverage is positively associated with several factors. The challenge of a high rate of girls' school attendance, information for the population and the inclusive organization of activities is a guarantee for the success of cervical cancer control through vaccination.

\section{References}

[1] Ferlay J, Soerjomataram I, Dikshit R, et al. Cancer incidence and mortality worldwide: sources, methods and major patterns in GLOBOCAN 2012. Int J Cancer 2015; 136: E359-386.

[2] De Vuyst H, Alemany L, Lacey C, Chibwesha CJ, Sahasrabuddhe V, Banura C, Denny L, Parham GP. The burden of human papillomavirus infections and related diseases in sub-saharan Africa. Vaccine. 2013 Dec 29; 31 Suppl 5: F32-46.
[3] Touré P, Ahmadou Dem B, Traoré MM, Dieng PS, Diop T, Ouajdi MT, et al. Gynecological and mammary cancers at the Dakar Cancer Institute. Cahiers Santé 2008. (18).

[4] Mboumba Bouassa RS, Prazuck T, Lethu T, Jenabian MA, Meye JF, Bélec L. Cervical cancer in sub-Saharan Africa: a preventable non-communicable disease. Expert Rev Anti Infect Ther. 2017 Jun; 15(6): 613-627.

[5] Lamontagne DS, Barge S, Nga TL, Mugisha E, and all. Human papillomavirus vaccine delivery strategies that achieved high coverage in low- and middle-income countries. Bull World Health Organ 2011; 89: 821-830.

[6] Odusanya OO, Alufohai EF, Meurice PF, Ahonkha VI. Determinants of vaccination coverage in rural Nigeria. BMC Public Health 2008, 8: 381.

[7] Vermandere H, Violet NV, Mabeya H and al.; Determinants of acceptance and subsequent uptake of the HPV vaccine in a cohort in Eldoret, kenya. plos one 9(10): e109353. doi: 10.1371 .

[8] Poole DN, Tracy JK, Levitz L, Rochas M, Sangare K, et al. A cross-sectional study to assess HPV knowledge and HPV vaccine acceptability in Mali. Plos one 8(2): e56402. Doi: 10. 1371.

[9] Hosmer DW, Lemeshow S. Applied Logistic Regression. New York: Wiley-Interscience; 2007.

[10] Ladner J, Besson MH, Rodrigues M et al. Performance of 21 HPV vaccination programs implemented in low and middleincome countries, 2009-2014. BMJ Health services research. 2016, 16: 575.

[11] Binagwaho A, Wagner CM, Gatera M, and all. Achieving high coverage in Rwanda's national human papillomavirus vaccination program bull world health organ. 2012; 90: 623628.

[12] Deborah WJ, Baisley K, and all. Human papillomavirus vaccination in Tanzanian schoolgirls: cluster-randomized trial comparing 2 vaccine-delivery strategies PLoS ONE 10(6): e0123701. doi: 10.1371 . 